$M \& W$ proposes to leap from this 'see-saw' by insisting that experience

FREEDOM, GRAMMAR AND THE GIVEN - MIND AND WORLD AND WITTGENSTEIN

\section{DENIS McMANUS}

This paper addresses an area of unclarity in John McDowell's Mind and $W{ }^{\prime} d^{1}$ and does so by drawing what appears to be a point of contrast between McDowell's views and those of Wittgenstein. McDowell presents Wittgenstein as one of his fellow travellers, as an important guide on the road to his own central insights. This paper will suggest that Wittgenstein would not be such good company for McDowell after all. In particular, from Wittgenstein's point of view, there remains a questionable rationalism in McDowell. This paper establishes a point of similarity between Wittgenstein and $M \& W$ over the idea that our thought about the world does not ultimately rest on a judgment of an unconceptualised given. For Wittgenstein, this establishes 'the autonomy of grammar', that concepts cannot be evaluated by how well they fit reality. $M \& W$, on the other hand, retains a notion of the evaluation of concepts, such that, in principle, any of our concepts can be revised. How we are to understand this notion is unclear but I will raise questions about the understanding of 'the revisability of concepts' to which McDowell appears to be wedded. I will go on to suggest that this problematic view sustains, and is sustained by, the residual influence on McDowell of a conception of the self as other-worldly and by a dubious commitment to the idea that the application of concepts is the exercise of freedom. ${ }^{2}$

$M \& W$ wishes to defend a 'minimal empiricism': 'the idea that experience must constitute a tribunal, mediating the way our thinking is answerable to how things are' (p.xii). How can experience do this? Firstly, let us consider what can, in principle, constitute a tribunal. McDowell plausibly asserts that 'we cannot really understand the relations in virtue of which a judgement is warranted except as relations within the space of concepts: relations such as implication or probabilification, which hold between potential exercises of conceptual capacities' (p.7). This thought can lead to the anxiety that thought is a 'self-contained game' (p.5), a 'frictionless spinning in a void' (p.11). In response, there arises the Myth of the Given, a vision of empirical justifications as having 'an ultimate foundation in impingements on the conceptual realm from outside' (p.6). McDowell argues that such a (necessarily inarticulate) pointing may appear to allay the fear of 'frictionless spinning' but that it does so only at the price of making it unintelligible how experience can provide reasons for our beliefs. must already be informed by concepts. Since '[e]xperiences already have conceptual content', justifying a claim by reference to experience 'does not take us outside the space of concepts' (p.10). In McDowell's favoured Kantian idiom, 'receptivity does not make an even notionally separable contribution' (p.9) to the co-operation between receptivity and spontaneity that constitutes experience. 'The relevant conceptual capacities are drawn on in receptivity ... [rather than being] exercised on an extra-conceptual deliverance of receptivity' (p.9). Hence, we are 'saddled with content' and concepts are in play 'before one has any choice in the matter' (p.10).

Throughout his development, Wittgenstein maintains a view that can be expressed as follows: thought cannot be a matter of judging how to ascribe concepts to an unconceptualised given. There is no judging how an entity might instantiate a concept as any such judgment presupposes what it was to establish. In this sense, there can be no explanation of how a proposition 'works', of how it represents. Any such explanation would presuppose what it was meant to explain. The following illustrative passage is a 1914 notebook entry:

[H]ow is congruence or non-congruence or the like given to us?

How can I be told how the proposition represents? Or can this not be said to me at all? And if that is so can I 'know' it? If it was supposed to be said to me, then this would have to be done by means of a proposition; but the proposition could only show it.

What can be said can only be said by means of a proposition, and so nothing that is necessary for the understanding of all propositions can be said. (NB, p.25) ${ }^{3}$

There can be no fact of the matter about how a proposition and the fact it represents relate. To know which part of reality to consider is already to know what the proposition represents and if one does not know which part of reality to examine, then the project of judging how the proposition represents cannot even begin. The supposed fact of 'fit' or its failure that we wish to judge has no content since we are being asked to evaluate "how this proposition relates to ...', a blank which can never be filled in without our presupposing that which we sought to determine. In this sense, there can be no such explanation of the proposition's capacity to represent. Our capacity to judge reality can only ever be a given:

The method of portrayal must be completely determinate before we can compare reality with the proposition at all in order to see whether it is true or false. The method of comparison must be given to me before I can make the comparison. (NB, p.23)

When we contemplate the mythic judgment that would bind a proposition to the world, we either take for granted how the two are bound or attempt to make a judgment the content of which must be indeterminate. In considering the fit between our proposition and a fact, we take for granted the relevance of this fact to this proposition. If we do not, in an effort to determine the proposition's meaning by assessing how it fits the world, we are then left with no idea which part of the world should be compared with the 
proposition. Thus, our basic relationship with meaning is not one of judgment and, instead, as 'the method of comparison', 'must be given me before I can make the comparison'.

In Wittgenstein's later Philosophical Remarks, we read the following articulation of the present point:

If I could describe the point of grammatical conventions by saying that they are made necessary by certain properties of the colours (say), then that would make the conventions superfluous, since in that case I would be able to say precisely that which the convention exclude my saying. (PR, p.53)

In stating the independently justifying fact, one either (a) repeats the description to be justified, in which case we have no independent, justifying reference point or (b) one gives another description. As a 1931 remark suggests, if we opt for (a), we fail to identify something that might justify the proposition's use:

The limit of language is shown by its being impossible to describe the fact which corresponds to (is the translation of) a sentence, without simply repeating the sentence.

If we opt for (b), there are, after all, other ways of talking about the subjectmatter and one does not need to use the kind of description that was to be justified. The conventions to be justified are not necessary after all and I can 'say precisely that which the conventions exclude my saying'. It turns out that the fact that would demand the description we are trying to justify can, after all, be described in other ways! The impossibility of the kind of justification envisaged forces us, then, to accept that concepts are, in this sense, 'arbitrary', that 'grammar' is 'autonomous'. A still later passage observes:

Why don't I call cookery rules arbitrary, and why am I tempted to call the rules of grammar arbitrary? Because 'cookery' is defined by its end, whereas 'speaking' is not. That is why the use of language is in a certain sense autonomous, as cooking and washing are not. You cook badly if you are guided in your cooking by rules other than the right ones; but if you follow other rules than those of chess you are playing another game; and if you follow grammatical rules other than such-and-such ones, that does not mean you say something wrong, no, you
are speaking of something else. $(\mathrm{Z}, 320)$

There seems to be important common ground here between Wittgenstein and $M \& W$. They appear to agree that there is no grasping or judging of a nonconceptualised Given on the basis of which a concept is then applied. The justification of our application of the concept that is sought here flounders on the fact that the perceived 'fit' between a concept and its subject-matter can only make sense if the subject-matter has already been conceptualised, if we already know how concepts apply to it. We are seeking to justify our method of comparison but can only set about doing so if that method is already given.

\section{II.}

The line of thought identified here suggests that, although we may come across what we call 'arguments over the conceptualisation of a domain', whatever these arguments turn out to be, they cannot be arguments over how to conceptualise a non-conceptually given 'world'. How, after all, would one address such a world? Without concepts, there is no issue to be considered, no question to be asked. The pseudo-judgment that addresses that non-conceptualised world is an inarticulate noise or a blank pointing gesture. Wittgenstein uses these insights in the service of an anti-rationalism, the identification of what, from a philosophical point of view, is a surprising absence of reasons. Yet, in $M \& W$, we find an opposed tendency, an emphasis on freely-applied, critical intelligence. For a Wittgensteinian, this represents a rationalism in $M \& W .^{5}$

Although $M \& W$ talks of our being 'saddled with content', it also invokes the metaphor of a 'network', by reference to which the choosing of concepts becomes possibly rational or irrational:

Active empirical thinking takes place under a standing obligation to reflect about the credentials of the putatively rational linkages that govern it. There must be a willingness to refashion concepts and conceptions if that is what reflection recommends. No doubt there is no serious prospect that we might need to reshape the concepts at the outermost edges of the system, the most immediately observational concepts, in response to pressures from within the system. But that no-doubt unreal prospect brings out the point that matters for my present purpose. This is that although experience itself is not a good fit for the idea of spontaneity, even the most immediately observational concepts are partly constituted by their role in something that is indeed appropriately conceived in terms of spontaneity.

So we cannot simply insulate the passive involvement of conceptual capacities in experience from the potentially unnerving effects of the freedom implied by the idea of spontaneity (pp.12-13).

Wittgenstein seems to suggest that there is no sense to the idea of reconstructing our concepts as a result of the world bucking. Concepts may fall into disuse, but they won't be corrected. $M \& W$, on the other hand, seems to suggest that there are connections between concepts that can result in those concepts being subject to critical revision:

[S]omeone who has [conceptual capacities] is responsive to rational relations, which link the contents of judgments of experience with other judgeable contents. These linkages give the concepts their place as elements in possible views of the world.

For example, consider judgements of colour. ... [N] o one could count as making even a directly observational judgment of colour except against a background sufficient to ensure that she understands colours as potential properties of things. ... The necessary background understanding includes, for instance, the concept of visible surfaces of objects and the concept of suitable conditions for telling what colour something is by looking at it (p.12).

Although '[n]o doubt there is no serious prospect that we might need to reshape the concepts at the outermost edges of the system', $M \& W$ declares that these connections are, in principle, 'essentially subject to critical reflection' (pp.12425). ${ }^{6}$ Even here we must be 'standing ready to reassess what is a reason for what' (p.114). '[T]he faculty of spontaneity carries with it a standing obligation to reflect on the credentials of the putatively rational linkages that, at any time, one takes to govern the active business of adjusting one's world-view in response to experience' (p.40), the 'rational relations, which link the contents of judgments of experience with other judgeable contents': 
The power of spontaneity comprises a network of conceptual capacities linked by putatively rational connections, with the connections essentially subject to critical reflection. [There is a] standing potential for a reflective stance at which the question arises whether one ought to find this or that persuasive (p.125).

I want to argue that a serious confusion threatens us here. The danger lies in talking of these connections as rational or irrational rather than as simply the connections that define the concepts in question. My principal criticism of $M \& W ' s$ remarks on the revision of concepts is that they create an illusion of a space for a kind of critical reflection where there is no such space.?

\section{III.}

The possibility of evaluating the connections that characterise our concepts emerges, for $M \& W$, from the fact that when, for example, one ascribes a colour to an object, what one says is 'fraught with implications' (p.32). But consider what happens if those implications are not confirmed, something that it is easy to contemplate as certain cases happen all the time and others can easily be imagined. We constantly come across collections of experience that break the rules of the concept 'the colour of an object'. We find that what we thought was the colour of an object was just an impression that we got as a result of a temporary alteration of the lighting conditions. Here we would say that we made a mistake. The concept still 'applies' but we got our judgment wrong. Or we ascribe a colour to something only to find that it does not really have a colour but instead constantly 'changes' colour. We could easily imagine some kind of 'super-chameleon', 'whose colour' constantly and perfectly matches that of its background. I use scarequotes in referring to 'its colour' and that colour 'changing' as, in connection with such a creature, it makes no sense to talk of 'its colour'. It 'has' a colour to the same degree as a piece of colourless glass 'changes its colour' as it passes in front of differently coloured objects. The upshot of describing such a case is the realisation that the notion of the creature's 'own colour', drawn upon in the very description itself, is of vanishing value here. ${ }^{8}$

Would our super-chameleon make us say that the concept of 'the colour to an object' did not make sense, that it stands in a set of irrational relations to other concepts? It seems more natural to say that we just would not use the concept here, that we expect nothing of the concept in these cases. There is nothing wrong with the concept in itself. It simply does not have a role here. ${ }^{9}$ And even then, depending on other factors such as what we are doing and what we happen to be interested in, we might find a use for the concept. We might be examining how the changing colour affects its skin pores and examine the creature in slow motion as the different colours wash over it. Then we might have found a use for talk of 'its colour'.

My suggestion then would be that concepts lose grip before they can be evaluated in the way that $M \& W$ imagines. ${ }^{10}$ The concept breaks off the world, loses its application, rather than renders itself vulnerable to revision or transformation so as to fit that world. $M \& W$ talks of 'a natural language, the sort of language into which human beings are first initiated', as 'a store of historically accumulated wisdom about what is a reason for what' and $M \& W ' s$ 'network' metaphor articulates a vision of a basis for the criticism of concepts. But if 'grammar' is 'autonomous', there can precisely not be 'wisdom about what is a reason for what' (p.126). The kinds of connection between concepts that $M \& W$ imagines our evaluating are internally related to those concepts, giving those concepts the identity that they have. Consequently, to imagine different, more rational linkages is to imagine other concepts, rather than the refining of existing concepts:

Everything which, if it occurred, would legitimately confirm a belief, determines logically the nature of this belief. That is, it shows something about the logical nature of the belief. (PR, p.87)

$M \& W$ talks of 'the putatively rational linkages that constitute the space of reasons as one conceives it at any time' (p.186). But according to Wittgenstein, it makes no sense to talk of different 'conceptions' of 'the space of reasons'. It might even be less misleading to say that a person with views on what constitutes a reason for a belief does not yet know what that belief is:

'How do you know that that really is the reason why you believe it?' - that is as. if I asked 'how do you know that it is that which you believe?'"

This is the core idea behind Wittgenstein's 'verificationist' claims:

Some people say that the question, "How can you know such a thing?", is irrelevant to the question, "What is the meaning?" But an answer gives the meaning by showing the relation of the proposition to other propositions. That is, it shows what it.follows from and what follows from it. It gives the grammar of the proposition, which is what the question, "What would it be like for it to be true?", asks for. ${ }^{12}$

McDowell talks of our 'standing ready to reassess what is a reason for what' (M\&W, p.114). But if concepts are defined by what constitutes a reason for what, to have different 'views' on such a matter is, at best, to be talking about different concepts. From this point of view, although we may reflect on whether some particular judgment, $p$, should be endorsed on the basis of a particular experience, wondering whether a particular kind of experience constitutes, as such, a reason for thinking that $p$ is a sign that we have not grasped $p$.

Wittgenstein talks, in On Certainty, of 'hinge propositions' and, in $\checkmark$ Philosophical Investigations, of different concepts being appropriate if we imagined certain general facts of nature being different. ${ }^{13}$ The failure of such facts to hold may constitute the kind of event that McDowell imagines challenging our use of certain concepts, since, should these facts fail, we would have to use different concepts. But Wittgenstein's point in picking out 
such facts is precisely to query the notion that the holding of these facts constitute grounds on the basis of which our critical faculty might see the use of certain concepts as justified. Such undoubted 'foundations' are not discovered through scientific investigation. Rather 'it belongs to the logic of our scientific investigations that certain things are in deed [in der Tat] not doubted' (OC, 342):

[T] he questions that we raise and our doubts depend on the fact that some propositions are exempt from doubt, are as it were like hinges on which those turn. (OC, 341)

We see this peculiar status in the fact that the 'falsity' of such claims would cast doubt on their very meaning. "[W] hat we call "measuring", for example, "is partly determined by a certain constancy in results of measurement', that constancy being 'part of the framework on which the working of our language is based' (PI, 240, 242). If a hinge proposition like: 'Very few objects behave like super-chameleons' were to fail, would we now be saying that the colour of objects varies like that of a superchameleon? Part of the point of saying that, is to say that there is now no point in saying that an object has a colour. ${ }^{14}$

Wittgenstein's perspective casts doubt on the notion that our coming to use different concepts in the light of certain facts failing, is a matter of our revising concepts, concepts which are, in themselves, more rational replacing those that are, in themselves, less rational. The recognition of hinge propositions and their peculiar status points us not towards a possible evaluation of concepts but towards the fact that our life as thinkers of thoughts is a worldly one. As such, it is dependent on certain facts about that world from which we cannot attain a critical distance - ' $[\mathrm{m}] \mathrm{y}$ life consists in my being content to accept many things' (OC, 344). That comfortable context makes available certain concepts, allows them to be used significantly. Our thought, our critical judgment in its different forms, lives in a world partly constituted by those facts and, as such, it is too intimately related to those facts for the one to stand in critical evaluation of the other.

IV.

The previous section closed by arguing that Wittgenstein's 'hinge propositions', upon which $M \& W$ lights without recognizing them as such, are an indication of the worldly condition of judgment, rather than a sign that the basic principles of our judgment can be subjected to critical reflection. The significance of these facts lies then in the way in which, should they change, we would not bother with certain descriptions, descriptions that would have become meaningless in the sense of 'pointless'. If there is anything to be called 'irrationality' in the concept, 'the colour of a superchameleon', it lies in the fact that there are vanishingly few cases in which its use would have a point, in which we could say anything significant using it. But is this best expressed by saying that their 'rational relations' fall under suspicion? Would we say that concepts that are very rarely used have linkages that are less rational? To give a further indication of why not (which will also extend my case for worrying that the McDowellian Subject pretends to a mythically other-worldly position), recall the circumstances in which we might continue to apply the concept of 'having a colour' even to our super-chameleon. Even in declaring the concept to be useless, we are assuming that we continue to engage in the same old activities. Perhaps there will still be a use for the concept for people engaged in different activities and with different interests.

I want to develop here Wittgenstein's emphasis on the inter-dependence of concept-use and lives. Concepts and descriptions are useful or not according to which activities we engage in and this relationship suggests that concepts are only as commensurable as the activities that they inform. Consider some of the uses of language that Wittgenstein lists in the Investigations: 'Giving orders, and obeying them, [d]escribing the appearance of an object, or giving its measurements, [c]onstructing an object from a description (a drawing) ... [f]orming and testing a hypothesis, $[\mathrm{p}]$ resenting the results of an experiment in tables and diagrams, [m] aking up a story and reading it ...[s]inging catches, [g]uessing riddles, [m]aking a joke [and] telling it, ... [a]sking, thanking, cursing, greeting, praying' (PI, 23). None of these activities are 'alternatives' to one another in anything other than some rather specific and superficial ways. One might fill one's time with any of the above or distract someone with any of the above. But, more typically, what we do when we greet someone is not something that we could have done instead (perhaps less well) by telling them a joke, and presenting the results of an experiment is simply a different business from giving orders. In recognizing the sheer daftness of any kind of critical comparison of these activities and, correspondingly, any grounding that some might thus be thought capable of receiving, one might conclude that '[w] hat has to be accepted, the given, is - so one could say - forms of life.' (PI, p.226).

At this level at least, to choose between concepts is then to choose between activities and only if the latter can be compared, can we sensibly choose between the former. What distracts us from this fact when reading $M \& W$ is the fact that one has very little sense of what the McDowellian subject does with its days, other than 'continually reshaping a world-view in rational response to the deliverances of experience' (M\&.W, p.114). One is left with an image of a subject that McDowell explicitly wants to challenge, that of 'the observer and thinker that does not act in the world it observes and thinks about' (M\&W, p.117). Through his conception of choice between concepts, McDowell presents a subject set back from its world and its 
worldly activities, with the exception of the rather other-worldly-sounding business of 'continually reshaping a world-view' ${ }^{15}$ And, of course, a benefit of this being the activity of the McDowellian subject is that it suggests that our concepts are fundamentally commensurable by virtue of all being tools to be used in a single activity. ${ }^{16}$

This perspective can be seen in McDowell's response to the possible collapse of what I have suggested are Wittgensteinian hinge propositions, that is, envisaging a rational intelligence constructing new tools in order to continue going about its business. But unless one's conception of that 'business' is as abstract as 'continually reshaping a world-view', one would recognize that a whole collection of basic activities would then have collapsed and that there is no other way of performing these with 'alternative concepts'. Consider the activities mediated by the idea of 'the colour of an object'. Might we switch instead to concepts of shape? Or texture? That might work where colours are used purely as labels. But what of painting, or choosing clothes? McDowell offers a vision of our picking ourselves up and trying again. But trying to do what? With concepts 'quite different from ours', 'life would run on differently' and what interests us now would not interest us then ( $\mathrm{Z}, 387-88)$.

I have so far suggested that, from a Wittgensteinian point of view, McDowell systematically overestimates the role played by critical reflection in the 'revision of concepts'. However, corresponding to my suspicion that McDowell's perspective is dangerously over-general, we must not plunge ourselves into an opposing and equally extreme counter-generalisation. After all, my suggestion that concepts are as commensurable as the activities that they inform leaves open the possibility that some form of reflection might play a role in some kinds of case that we could label 'choosing between concepts'. But what kind of reflection would this be? ${ }^{17}$

Since there are an indefinite number of potentially powerful ${ }^{18}$ and perfectly coherent descriptions of 'the world' available to us, we seem to be left with reflection on the usefulness of descriptions, their fruitfulness for creatures like us, with interests and activities like ours or close relations to those interests and activities. In addition to more straight-forwardly pragmatic concerns, we touch here on the Nietzschean theme of the value of truth. By that I mean not a scepticism about the 'reality' of truth but an awareness that truths are embedded in ways of life, that to ask certain questions is to live a certain way. The fantasy of a 'non-autonomous' grammar is precisely that of a world which tells us which questions to ask. not just the answers to the questions we ask. Subject-matters would then not just the answers to their own that we ought to strive to learn, nature itself telling us how it should be treated. ${ }^{19}$ I would suggest that concern with this myth and the many different forms in which it may insert itself into our thought has a profound shaping influence on Wittgenstein's thought throughout his development. Exposing that myth, we will see that the rationality of, and our responsibility for, the questions we ask has more to do with our responsibility for how we live than with our responsibility for what we come to believe. Are such issues illuminated by talk of rational and irrational connections between concepts? If reflection on 'conceptformation' does indeed cross the territory to which I have just pointed, this would be invisible to our 'observer and thinker' who, after all, 'does not act in the world it observes and thinks about'. At best, these issues would present themselves as odd forms of fact about the juxtaposed and distanced world, perhaps as facts that those concepts that are 'rationally-linked' will reflect. Our activities may lose their sense, may become pointless, and may do so for a host of potentially articulable reasons. My worry is that McDowell mythologizes the causes of this collapse by his invocation of irrationalities in the linkages that make up the concepts themselves.

It is a lesson of Nietzsche, Kierkegaard and, on some readings, Wittgenstein that philosophy characteristically converts problems with our lives into problems with our beliefs and responsibilities for our actions into care over our world-view. ${ }^{20}$ The characteristic product of this projection is the metaphysical fact that would determine grammar. But in McDowell's suggestion that concepts are revised on the basis of reflection on the linkages that constitute them, the postulation of those assessable linkages seems to perform a similar function, projecting our lives and their tensions outwardly on to a subject-matter to be known. We are presented then with a collection of confusions, threats of meaninglessness and species of pointlessness for which our concepts themselves are held responsible when perhaps the responsibility lies with ourselves.

Some tentative examples of the kinds of 'conceptual choice' I have in mind might be: educating to produce thinkers as opposed to effective workers, playing to win as opposed to playing for the love of the game and understanding the treatment of the mentally ill as a process of getting them to see the truth as opposed to getting them to be content. In all of these cases, the 'phenomena' in question are describable in terms of both rival conceptual schemes. One can produce accounts that would be equally correct in their own terms and assessable as correct applications of the concepts in question. In these senses, the 'linkages' of the concepts in both cases may be impeccable. Hence, reflection upon these 'linkages' will not illuminate these disturbing and very real 'choices between concepts' or the responsibility that we may accept or reject for those choices. I do not pretend that the nature of the reflection that we engage in over such issues is clear. But it seems to me that the overall tendency of the McDowellian perspective on the self and its concepts is to hide the existence and character of this form of reflection. 
Here we skirt perilously close to a long tradition of philosophical fantasising that has striven to disguise the difficulties with which this form of reflection presents us by disguising that reflection as a species of theoretical reflection. ${ }^{21}$

V.

$M \& W$ is an ambitious work which its author acknowledges to be 'unguarded' and sometimes 'two-dimensional' (M\&W, pp.vii-viii). It is a difficult work to pin down. At times, it makes what are, from my point of view, 'all the right noises', in challenging, for example, the notion of 'external validation' and of a 'side-ways view' ${ }^{2}$ - though a work that can talk, for validation' and of a 'side-ways view' 22 - though a work that can talk, for
example, of a 'naturalised platonism' will inevitably make everyone happy some of the time. I have suggested that the picture of the self and its concepts M $W$ genat the picture of the self and its concepts that seems to emerge from $M \& W$ generates an illusion of a space of reflection where there is no such a space and disguises the nature of reflection where 'reflection on the choice of concepts' does make a certain kind of sense. Some may think, however, that I am uncharitably making a great deal of what is just a difference in emphasis, that McDowell would not find anything in what I have said to which he would take serious exception. I have talked of concepts being abandoned, M\&W talks of their being refashioned. One migh argue that I am pointing out, at most, unfortunate turns of phrase in $M \& W$ and that its talk of a perspective on the 'putatively rational linkages between concepts' (p.125) is really just another way of describing the very processes of conceptual 'change' that I have articulated. Is there then anything more than a difference in idiom here? And is it anything more than a difference of idiom in the discussion of what is, in any case, a minor theme in $M \& W$ ? It is lack of amplification and clarification in $M \& W$ that nurtures the worries have presented here and that same lack does indeed render it unclear whether $M \& W$ really does endorse the problematic views to which those worries attach. But in this section, I will explain why it would be very natural for $M \& W$ to embrace these problematic views in the light of a related confusion that does seem to lie at the book's heart, a confusion arising from its broader sympathy for the language of spontaneity and freedom.

A possible source for this commitment is the set of connections that McDowell sees between ideas of spontaneity and freedom, normativity, responsibility and justification. For example, he points to the use of concepts in 'free thought' as a way of indicating that capacities at work in experience are conceptual too. ${ }^{23}$ What would perhaps help explain a commitment to a vision of a deep normativity, of a space of reasons that we more or less perceive and of concepts whose linkages might be more or less rational, is a corresponding commitment to a deep freedom. Sometimes $M \& W$ is willing to give 'freedom' a very bland gloss, such as 'responsiveness to reasons'
(M\&W, p.xxiii). But with our grasp of concepts, $M \& W$ seems willful in its desire to make this an exercise of freedom, to make this normativity an instance of our thinking in a manner which is, in some sense, qualitatively continuous with critical reflection. With the application of concepts, we need to conform to the rules in order to use a term intelligibly. But to say that the rules for its use constitute reasons to which we should be responsive seems wrong. As Wittgenstein emphasises throughout his work, we do not grasp the rules until we can follow them correctly. ${ }^{24}$

Compare the idea of our having a responsibility to believe what is true. We are described as irrational if we don't. But breaking such a rule seems less like the exercise of freedom and more like a descent into noise. Consider then the conditions for saying that someone has grasped a concept. There has to be a certain discipline in their use of a concept for us to say that they have grasped it, that they are indeed using it. But should they fail, their 'irresponsibility' is not a freedom, for instance, to make mistakes. Instead it is eithe the freedom to talk about some other issue or the freedom to say nothing, to descend into confusion. There is not a great deal of sense that can be attached to a notion of 'getting it right', of a 'responsiveness to reason', in either case. In the first case, the envisaged conflict might be illustrated by the 'conflict' in which I say 'That's red' and you say 'No, it's new'. In the second case, this breaking of rules is barely intelligible as an option that one might choose and, consequently, neither can the contrasting decision to keep to these rules. The envisaged alternative is not an alternative course of action but the disintegration of action.

Conforming to the rules that constitute our concepts is then a responsiveness to reasons only in the sense that we now recognize reasons, that we can now have thoughts that actually have a determinate content. That is not a 'view-point' that we might be convinced to adopt. ${ }^{25}$ Only now are we 'subjects who are in charge of their thinking' (M\&W, p.114). The choice that one makes in failing to conform to the relevant rules here is, at best, the choice to talk about something else or, at worst, the 'decision' to talk about nothing. If some people do not respond to the right considerations, we say that they haven't 'got it'. If they do, then they are now capable of talking with us, of sharing thoughts, and are now capable of critical reflection working up from here. Just because there is a rule here and hence, normativity, does not imply that there is space for intelligible reflection, for criticism, or for choice. ${ }^{26}$ Something certainly can 'go wrong' here. We can lose contact with one another and come to think of the other as simply talking nonsense. But in our arriving at this outcome, does the kind of 'responsibility' displayed merit the label, 'freedom'? It seems more natural to describe this supposed 'freedom' as that which makes real freedom possible, this supposed 'responsiveness to reasons' as that which makes reasoning possible. Wittgenstein observes that '[a] person can doubt 
only if he has learnt certain things; as he can miscalculate only if he has learnt (t) kind of basic rules that define our concepts, what she is failing to do is indeterminate, just as that define our concepts, what she is trying to do. ${ }^{27}$

This commitment leads McDowell to force the possibility of critica reflection into spaces in which it does not belong. The mastery of basic concepts is indeed a responsiveness to reasons but only in the sense that that mastery makes reasoning and critical reflection possible. The breaking of these rules is a descent into noise; therefore the observation of these rules cannot be seen as an achievement brought about by our critical intelligence. Rather, through that mastery, we first come to achieve intelligence. It is not that we come to think rationally, or 'well' in some other sense. $M \& W$ 's account of the irrationality of breaking the norms that govern the very possibility of contentful judgment seems to be either a misidentification of the simple possibility that we may change the subject or an underestimation of how darkly senseless the irrationality is that engulfs us when those norms are violated. The 'conflict' between those who obey and those who break these rules is one marked by silence. It is not a clash over an issue but the these rules is one marked by silence. It is not a clash

McDowell and Wittgenstein agree that, if we ever intelligibly talk of 'revision of concepts', the 'mechanism' involved cannot be the 'comparison' f a concept with an unconceptualised 'Given'. Nevertheless, there can be no doubt that we sometimes talk of the revision of concepts in science and in athics, for example, and there may be very good reasons why we should describe some of those revisions as, in some sense, rationally-governed. My describe some of those revisions as, in some sense, rationally-governed. My principal complaint against McDowell is that when, perhaps with good reason, he strives to make room for something that can be called 'critical evaluation of concepts', he does so by introducing a general account of the relationship of concepts, reflection and responsibility which, if its generality is to be taken seriously as McDowell's broader concerns seem to require, threatens to lead us into nonsense. I have suggested that when we consider how we may come to withdraw the use of a concept like 'the colour of an object', it is difficult to see how that constitutes criticism of their 'putatively rational linkages'. I have gone on to contextualise the rationalism that seems to lurk in $M \& W$ in two related ways. I have suggested that it supports, and is supported by, a certain fixation on thought as 'free' and a certain tendency to think of the self as other-worldly. The latter is clearly counter to McDowell's own intentions but his attitude towards the revision of concepts makes more sense if we ascribe to him a residual temptation to think in that way. $M \& W$ is, in many respects, a deeply admirable work. I hope that my criticisms might at least elicit some clarification of the perspective set forth there.

University of Southampton
References

1. Cambridge, MA: Harvard University Press, 1994, henceforth referred to as $M \& W$. The essays by McDowell cited here are reprinted in his Mind, Value and Reality (Cambridge, Mass.: Harvard University Press, 1998). Page references are to this volume.

2. I would like to thank several people for their comments on earlier versions of this paper. These include Andrea Kern, an anonymous referee for the JBSP and participants in the conference, 'McDowell's Mind and World', held at the Cambridge Centre for Research in Hermeneutic and Analytic Philosophy (for which this paper was initially written). I have also benefited from conversations on the paper's topics with James Conant and colleagues of mine at the University of Southampton (who took part in a reading group devoted to $M \& W)$.

3. When referring to certain frequently cited works by Wittgenstein, the following abbreviations (followed by page or section number) are used: NB - Notebooks 1914-16 (ed. G.H. von Wright and G.E.M. Anscombe, trans. G.E.M. Anscombe, Oxford: Blackwell, 1979), von Wright and G.E.M. Anscombe, trans. G.E.M. Anscombe, Oxford: Blackwell, 1979),
OC - On Certainty (ed. G.E.M. Anscombe and G.H. von Wright, trans. D. Paul and OC - On Certainty (ed. G.E.M. Anscombe and G.H. von Wright, trans. D. Paul and
G.E.M. Anscombe, Oxford: Blackwell, 1974), PI - Philosophical Investigations (ed. G.E.M. Anscombe and R. Rhees, trans. G.E.M. Anscombe, Oxford: Blackwell, 1967), PR - Philosophical Remarks (ed. R. Rhees, trans. R. Hargreaves and R. White, Oxford: Blackwell, 1975) and Z - Zettel (ed. G.E.M. Anscombe and G.H. von Wright, trans. G.E.M. Anscombe, Oxford: Blackwell, 1981).

4. Culture and Value (ed. G.H. von Wright, trans. P. Winch, Oxford: Blackwell, 1980), p.10.

5. McDowell is, of course, himself an influential interpreter of Wittgenstein. His understanding of the significance of Wittgenstein's so-called 'private language argument' (cf. $M \& W$ pp.18-23 and 'One Strand in the Private Language Argument') reflects the points of similarity identified in the previous section. But I shall be arguing that his broader philosophy arrives at conclusions that Wittgenstein would reject. Cf. also n.28 below.

6. Does it make any sense in the first place for McDowell to talk about different conceptualisations being possible? If we are 'saddled' with concepts from the off, how can there be something that is conceptual-ised? (His suggestion that the conceptualised is 'the world' is clearly meant principally as a way of forestalling the question (p.39)) One might argue that what we are referring to as 'our choice of concepts' is something that happens at the level of judgment, in choosing which appearances to endorse as real. The concepts that we reject would then be those which articulated appearances that we ceased to endorse. This view (which appears to be at work in the third lecture of $M \& W$ and its postscript) still faces problems. For example, it seems to Conant has suggested to me). But it offers a prima facie McDowell's view of reconceptualisation might be workable.

7. In addition to its sustaining a view of the role of freedom in thought (examined and criticised in the final section of this paper), McDowell can exploit this illusion in at least two further ways. Firstly, he invokes his account of the potential revisability of observational concepts as a demonstration that conceptual capacities are at work in experience (M\&W, cf. pp.13, 32-34). McDowell has other, and to my mind, better arguments in favour of this same view. Secondly (and more speculatively), I also suspect that McDowell wants to ensure that there remains room for certain kinds of conceptual revolution, in the wants to ensure that there remains room for certain kinds of conceptual revolution, in the
ethical and scientific domains. His rejection of an 'extra-conceptual deliverance of ethical and scientific domains. His rejection of an 'extra-conceptual de
receptivity' (M\&W, p.9) might seem to render that impossible (cf. n.7 above).

8. One might even say, mimicking section 6.54 of Wittgenstein's Tractatus, that to understand the point of the description is to see that the description itself does not quite make sense.

9. Compare the following remarks of C.I. Lewis, noting, in particular, their conclusion: 'It is an a priori principle that physical things must have mass. By this criterion, they are dirtinguished from minor-images and illusion. Since this is so, no particular experience could 
reptitiated as non-veridical or "not correctly understood." That is, by the principle itself, the phenone the thuth of the principle is independent of the particular phenomenon. But a world in the. Truth of the principle is independent of the particular phene and independence not per characteristic of imagination, and a coherence not characteristic of our dreams, but thing which would still not be amenable to any gravitational generalizations, is entirely conceivable. In such a world our a priori principle would not be rendered false - since it is definitive of the physical; but the category "physical" might well be useless. (Mind and the World-Order (New York: Charles Scribner's Sons, 1929), pp.26-27).

10. $M \& W$ itself suggests that the prospect of concepts like that of 'the colour of an object' being revised is 'no-doubt unreal'. But it is the one example that he gives that allows us to

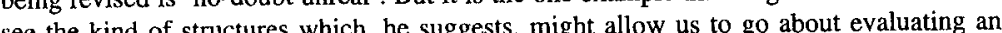

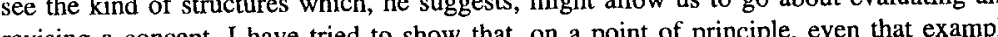
revising a concept. I have tried to show that, on a point of principle, even that example resists the vision of critical reflection that McDowell offers

11. 'The Big Typescript', unpublished typescript no. 213, p.402. The translation is my own, the original typescript passage being: "Wie weisst Du, dass das wirklich der Grund is weswegen Du es glaubt?" - (das) ist, als fragte ich: "wie weisst Du, dass es das ist, was Du glaubst?".

12. Wittgenstein's Lectures Cambridge 1932-35 (ed. A. Ambrose, Oxford: Blackwell, 1979), pp.19-20.

13. Cf. OC, pp. $341,343,655$ and PI, p. 230

14. Compare PI, p.226: 'Does it make sense to say that people generally agree in their judgments of colour? What would it be like for them not to? - One man would say a flower was red which another called blue, and so on. - But what right should we have to call these people's words "red" and "blue" our 'colour-words"? ... [I]s the language-game which they learn still such as we call the use of "names of colour"?

15. $M \& W$ p. $10 \mathrm{n} .8$ insists that 'experiencing the world involves activity', that '[s]earching is an activity [and] so are observing watching and so forth'. But the notion that particular concepts might be inter-dependent with particular activities does not emerge.

16. An obvious parallel here is the difference in views of the use of language in the Tractatus (a monolithic 'picturing the world') and the Philosophical Investigations (cf. the list of uses from PI, p.23 quoted below).

7. I also do not wish to rule out the possibility that the mechanism behind some kinds of conceptual revolution in science might approximate to that sketched by McDowell. Although I am unsure of how illuminating that sketch is even there, my principal worry is the generality with which McDowell sets forth that mechanism.

18. I assume bere that only a dubious physicalism would make one assert that physical descriptions are the single, ideal basis upon which to understand social problems or win a football game.

19. McDowell sounds a similar note, and echoes his own claim that the Given promises exculpations if not justifications $(M \& W, p .8)$, when he suggests that the postulation of 'things in themselves' expresses 'an intelligible wish to avoid responsibility' ('Two Sorts of Naturalism', p.181).

20. Cf., e.g. the discussion of Wittgenstein and Kierkegaard in James Conant's 'Must We Show What We Cannot Say?' (in The Senses of Stanley Cavell (ed. R. Fleming and M.Payne (Lewisburg: Bucknell University Press, 1989)) and 'Kierkegaard, Wittgenstein and Nonsense' (in Pursuits of Reason (ed. T. Cohen, P. Guyer and H. Putnam (Lubbock: Texas Tech University Press, 1992)).

21. Although McDowell's hope that he might come to an adequate understanding of our lives as concept-users also rests on Aristotle, he concedes that Aristotle will tell us little about the radical revisionist reflection that he postulates and the only detail that he fills in in his the rant of this reflection is that it will be 'Neurathian', taking place 'only from the midst of the way of thinking one is reflecting about' (M\&W, p.81) (cf. also 'Some Issues in
Aristotle's Moral Psychology' (especially pp.36-38) and 'Two Sorts of Naturalism' (especially pp.188-95)). This aversion to the concrete is not, I am sure, without motivation. - Why should McDowell say any more than he has to? - But, as I have argued above, the soil here left unturned is where several of the philosopher's greatest critics have claimed its roots lie.

22. Cf. the discussion of Peacocke in the Postscript to Lecture III of $M \& W$.

\section{Cf. n.8 above.}

24. My objection here echoes that articulated in a Kantian context by Alan Thomas in his 'Kant, McDowell and the Theory of Consciousness' (European Journal of Philosophy 5 (1997), pp.283-305). My proposal is that the conception of concept-ascription in question marks a profound point of difference between $M \& W$ and Wittgenstein in particular.

25. There appears to be some kind of recognition of the proposal I am making here in the suggestion in 'Two Sorts of Naturalism' that we cannot be understood as 'conscripts', opposed to 'volunteers' to reason's 'army' because we 'were not in a position to hear its reason's categorical demands' (p.197). My point, perhaps echoed here, is that consequently, in coming to master our basic concepts, we cannot be seen as conscripts or volunteers. But McDowell seems to equivocate in what it is to be 'responsive to reasons', sometimes allowing this notion to suggest something like having a perspective on reasons.

26. In 'Two Sorts of Naturalism', McDowell insists that 'reason is inherently open to reflective questions about the rational credentials of the way it sees things' before suggesting that when reflecting on a conceptual organization of a particular sphere, 'if what is in question really is something conceptual, it is escential to it that reflection can break out at any tim' (p.190). He does also refer to 'limits on the course reflection can intelligibly take, which come out in limits on what can be intelligible in the way of statements that purport to express part of such reflection' (p.190). But it seems to me that his faith in the indefinite power and range of reflection contributes more to McDowell's overall philosophy and does so to its detriment. The range of intelligible reflection may indeed be indefinite in the sense that it may be impossible to demarcate its limits in an a priori fashion. But that does not preclude the possibility that we may imagine spaces for reflection which are in fact, illusory.

27. It is unclear to me how the perspective criticised here relates to that which McDowell extracts from Wittgenstein (and appears to endorse) in his 'Wittgenstein on Following a Rule'. Although McDowell consistently maintains that critical reflection is 'Neurathian', the kind of intellectual respectability that he suggests any concept might, in principle, be shown to possess appears to me to presuppose another (perhaps different) form of 'diggin beneath bedrock' (cf. especially sec. 11). Put another way, there may be more ways of slipping into the pursuit of a problematic form of 'external validation' than the explicit search for a 'first natural' account of meaning.

28. Another way of characterising the challenge to which the present section responds is Where does 'the standing obligation' come from? One other guess would be that it constitutes a response to McDowell's well-founded horror of 'givens' and that he inherits an anti-foundationalist conception of rationality from Sellars: '[E]mpirical knowledge, like its sophisticated extension, science, is rational, not because it has a foundation but because it is a self-correcting enterprise which can put any claim in jeopardy, though not all at once.' (Empiricism and the Philosophy of Mind (Cambridge. Mass. Harvard Univerity Press,

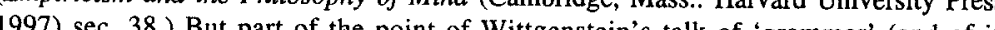
(9) extension in the direction of 'hinge propositions') that McDowell seems to have missed, is that there are certain 'claims' that are, in an unmysterious way, set back from any 'web of belief'. The challenge is to understand this peculiar status without recourse to a constructive philosophical explanation, in terms of an 'exogenous' or an 'endogenous Given', Platonic forms or 'meaning bodies' (PI, p.559). 